\title{
"Cada Caso é um Caso": as moralidades situacionais nos acordos envolvendo pensões alimentícias entre ex-cônjuges
}

\author{
"Each Case is a Case": situational moralities in divorce alimony \\ agreements
}

\author{
Marcella do Amparo Monteiro Freire ${ }^{1}$
}

Michel Lobo Toledo Lima ${ }^{2}$

\section{RESUMO}

No presente artigo descrevemos e analisamos audiências observadas de casos de pensão alimentícia para ex-cônjuges em Varas de Família no Estado do Rio de Janeiro entre 2019 e 2020. A problemática aqui explorada se dá com a contradição percebida entre as moralidades situacionais que orientam as decisões dos juízes, o que é traduzido na categoria nativa "cada caso é um caso", e o princípio da segurança jurídica, pautado, principalmente, na previsibilidade de decisões em casos semelhantes. Há uma tensão paradoxal entre práticas e ideais doutrinários do direito, no campo judicial. Os dados do trabalho de campo demonstram que os magistrados decidem orientados por diversas perspectivas morais, sem que existam critérios específicos aptos a orientar os resultados a serem esperados pelos jurisdicionados, acabando por gerar insegurança jurídica.

\section{PALAVRAS-CHAVE}

Moralidade. Vara de Família. Amor. Pensão alimentícia.

\begin{abstract}
In the present article we describe and analyze judgments of divorce alimony payment cases in Family Courts in the State of Rio de Janeiro between 2019 and 2020. The problematic explored here is the perceived contradiction between the situational moralities that guide the judge's decisions, which is translated into the native category "each case is a case", and the principle of legal security, based mainly on the predictability of decisions in similar cases. There is a paradoxical tension between the practices and doctrinal ideals of law in the judicial field. The data from the field work demonstrates that the magistrates decide guided by several moral

\footnotetext{
${ }^{1}$ Mestre em Direito pela Universidade Veiga de Almeida (UVA); especialista em Direito Privado e Processo Civil pela Universidade Gama Filho (UGF); especialista em Direito pela Escola de Magistratura do Estado do Rio de Janeiro (EMERJ); graduada em Direito pela Universidade Gama Filho (UGF); analista do Ministério Público do Estado do Rio de Janeiro.

${ }^{2}$ Doutor e mestre em Sociologia pelo Instituto de Estudos Sociais e Políticos da Universidade do Estado do Rio de Janeiro (IESP/UERJ); pós-graduado em Políticas Públicas de Justiça Criminal e Segurança Pública pela Universidade Federal Fluminense (UFF); graduado em Direito pela Pontifícia Universidade Católica do Rio de Janeiro (PUC-Rio); professor visitante do Programa de Pós-graduação em Direito da Universidade Veiga de Almeida (PPGD-UVA); pesquisador de pós-doutorado FAPERJ nota 10 no PPGD-UVA; pesquisador do Instituto de Estudos Comparados em Administração Institucional de Conflitos (INCT/InEAC-UFF).
} 
perspectives without there being specific criteria capable of guiding the results to be expected by the courts, which ends up generating legal insecurity.

\section{KEYWORDS}

Morality. Family Court. Love. Alimony.

\section{INTRODUÇÃO}

O presente artigo versa sobre conflitos de natureza familista, através da análise das audiências com pleitos de pensão alimentícia envolvendo ex-cônjuge, a fim de descrever como as moralidades dos julgadores influenciam as suas decisões para tais demandas e, por consequência, a vida dos jurisdicionados, contrariando a premissa da segurança jurídica que visa ter previsibilidade e transparência nas decisões judiciais.

A pesquisa ${ }^{3}$ foi composta por três métodos em diferentes momentos: a pesquisa de campo com observação direta das audiências presenciais por um período de três meses, semanalmente, sendo dezenove audiências nas Varas de Família; as entrevistas abertas, sem questionários formulados anteriormente, realizadas com cinco magistrados titulares de Varas de Família, todos do Tribunal de Justiça do Estado do Rio de Janeiro; e, por fim, foi possível observar presencialmente doze audiências virtuais ${ }^{4}$, também em Varas de Família no Rio de Janeiro.

\footnotetext{
3 Este artigo traz parte de pesquisa de mestrado em Direito na Universidade Veiga de Almeida. Veja a pesquisa completa em: FREIRE, Marcella do Amparo Monteiro. "O Amor Acaba": um estudo sobre as moralidades aplicadas na prática das varas de família. Dissertação (mestrado em Direito) - Programa de Pós-Graduação em Direito, Universidade Veiga de Almeida - RJ, 2021. Parte do debate aqui descrito também foi apresentada no GT Formas Consensuais de Solução de Conflitos do I Evento Virtual do Conselho Nacional de Pesquisa e PósGraduação em Direito (CONPEDI). Disponível em:

<http://conpedi.danilolr.info/publicacoes/olpbq8u9/00a6sk12/C0zOAIXPkVAe7DPf.pdf >. Acesso em: 20 mar. 2021.

4 Um pouco mais de dois meses após iniciar a pesquisa de campo, o mundo foi acometido pela pandemia da COVID-19. Diante da interrupção de todos os serviços prestados pelo Poder Judiciário durante o trabalho de campo, foi necessário repensar os acessos ao campo. A observação de audiências virtuais e a realização de entrevistas abertas por videochamada mostrou-se uma boa resposta para a continuidade da pesquisa. As observações presenciais de audiências virtuais ocorreram respeitando todos os protocolos de vigilância sanitária
} 
O trabalho de campo possibilita ao pesquisador maior contato com a realidade vivida pelos jurisdicionados para identificar o impacto das decisões na vida de quem busca o Poder Judiciário. No decorrer no texto foram usados nomes fictícios para nos referirmos às partes envolvidas nas demandas judiciais analisadas, além dos magistrados, promotores de justiça e servidores públicos, sempre indicando, além dos nomes fictícios, algumas características das pessoas observadas em campo, como sexo, cor, escolaridade, ocupação, entre outras particularidades, com o fim de possibilitar melhor aproximação das histórias com o leitor, para caracterizar os envolvidos nas demandas de forma "humanizada".

Assim, visa-se ir além de uma relação simples de autor ou de réu da ação judicial. Trouxemos uma possível identidade dos interlocutores durante a pesquisa de campo realizada em um local empírico específico. Assim, visamos não só manter as identidades de "carne e sangue" com as pessoas cujas interações foram observadas durante o trabalho de campo, mas também posicionar e situar, embora que brevemente em alguns casos, as ações e os discursos analisados (ELBAUM, 2010, p. 24). Quando for possível identificar a classe social das partes, também a demonstraremos no texto, mas durante a pesquisa este não foi um dado colhido de forma essencial. Roberto Kant de Lima (2008, p. 11) traz esta questão:

Embora estudando um lugar em que o método o leva a trabalhar em "pequena escala", não é esse o seu "objeto" (....). Não está aí estudando "um sistema de parentesco", "um sistema jurídico", "uma comunidade", sobre os quais enunciará um discurso limitado pela sua "pouca" capacidade de generalizar. A passagem da quantidade à qualidade não é empírica, mas teórica. É porque está estudando "em um tribunal", com experiências específicas e concretas, estabelecendo relações que se podem exprimir em "casos" e a partir deles, é que a experiência qualitativa da Antropologia é geral e desvendadora da capacidade das generalizações ocas e das especificidades rasteiras.

Assistir audiências em Varas de Família depende de permissão não só do juiz responsável pela audiência, mas também da autorização expressa das partes envolvidas 5 . Apesar disso, não houve casos de pessoas que se opuseram às observações feitas em campo.

relativos à pandemia e ao isolamento social, que podem ser consultados em: <http://www.tjrj.jus.br/noticias/noticia/-/visualizar-conteudo/5111210/7305558>. Acesso em: 20 mar. 2021.

5 Há pontos metodológicos importantes que traremos, mesmo que brevemente. Foi apresentada aos interlocutores da pesquisa, e nas audiências observadas em campo, a possibilidade de anonimato ou não. Mesmo que nem todos, sejam operadores do Judiciário, ou não, tenham requisitado seu anonimato, a escolha foi por não identificar seus nomes reais, embora essa questão não tenha sido colocada como um problema para nenhum dos interlocutores e observados na pesquisa de campo. 
Ademais, um número significativo de audiências era desmarcado em razão de a parte não ter sido encontrada para intimação da audiência ou sequer havia sido feita a citação da parte ré, bem como pela ausência de alguma testemunha ou documento importante.

Por fim, a problematização aqui explorada se dá com a contradição percebida entre as moralidades situacionais que orientam as decisões dos juízes, o que é traduzido na categoria nativa "cada caso é um caso", e o princípio da segurança jurídica, pautado, principalmente, na previsibilidade de decisões em casos semelhantes. Há uma tensão paradoxal entre práticas e ideais doutrinários do direito.

A doutrina do direito preconiza a segurança jurídica nas decisões judiciais e nos julgamentos dos tribunais brasileiros, no sentido de que os casos devem ser tratados de forma isonômica, e, por isso, faz-se necessário haver uma previsibilidade nas decisões judiciais em casos semelhantes. Maria Sylvia Zanella Di Pietro (2019) traz o princípio da segurança jurídica como escopo de gerar estabilidade e previsibilidade nas relações submetidas ao Poder Judiciário, citando, inclusive, os incidentes de uniformização de jurisprudência e das súmulas como instrumento da aplicação deste princípio. O objetivo seria julgar casos semelhantes de forma igualitária e uniforme, para manter o tratamento isonômico entre os casos e as partes que buscam o Poder Judiciário a fim de solucionar seus conflitos, tendo como forma de proteção jurídica a previsibilidade das decisões judiciais. Todavia, os casos observados em campo eram conduzidos pelas autoridades judiciárias de forma diferente, mesmo que possuíssem características semelhantes e sem parâmetros explícitos que diferenciem tais decisões. Percebemos que os juízes aplicam moralidades situacionais, através de interpretações e interações específicas, caso a caso, que dependem de algumas interações pontuais e contextuais entre os agentes envolvidos no contexto. Lucía Eilbaum (2010, p. 23) em sua tese afirma:

o que me interessa aqui é o fato da ação judicial estar informada por moralidades diversas, resultando em um processo de consolidação jurídica de certos valores morais - e exclusão de outros (...)

Assim, não se trata aqui de identificar "uma" moral ou "uma" ética específica, mas de propor a presença, em um determinado contexto institucional judicial, de "moralidades situacionais". Por isso, acredito que os valores morais que informam as ações e decisões judiciais não sejam nem únicos, nem homogêneos nem imutáveis, derivados de uma estrutura social totalizante. 
Portanto, buscamos identificar, de acordo com as pessoas envolvidas nos casos, e nos contextos vividos nas demandas observadas, em razão da natureza dos conflitos, como as decisões e os acordos analisados foram construídos, a fim de entender a relação existente entre a administração de justiça nos casos de pensão alimentícia nas Varas de Família e as possíveis moralidades, bem como os interesses que informam a prática (EILBAUM, 2010, p. 24).

\section{ENTRE O FAZER JUDICIAL E O FAZER ANTROPOLÓGICO: OS DESAFIOS DA ESCRITA}

Além das dificuldades comuns de acesso ao campo de pesquisa, sobretudo no contexto da pandemia do coronavírus, outra questão que surgiu, na etapa da escrita da pesquisa, foi o desafio em se despir da escrita jurídica para escrever de forma acadêmica, com naturalização da nossa escrita jurídica, empregando jargões e palavras específicas do direito. Uma ilustração disso se dá com a categoria nativa "ato contínuo", trazendo para a escrita acadêmica termos usados diariamente no campo de atuação profissional ao elaborar as minutas dos pareceres jurídicos. O termo "ato contínuo" visa reduzir a descrição e eliminar supostas subjetividades de atos observados em audiências judiciais, para fins de facilitar a escrita de relatórios burocráticojudiciais, justamente o oposto ao que a pesquisa de campo, de orientação etnográfica, por exemplo, se propõe a fazer, ou seja, é uma descrição densa em que o pesquisador enfrenta a multiplicidade de estruturas conceituais complexas, muitas delas sobrepostas ou amarradas umas às outras, simultaneamente estranhas, irregulares e inexplícitas, e que ele precisa, de alguma forma, primeiro apreender e depois apresentar (GEERTZ, 1978, p. 20).

Para além da categoria ato contínuo, também explicitamos que, em razão da nossa formação em Direito, tivemos uma sociabilidade profissional voltada a não descrever detalhes, enquanto a escrita acadêmica se dá no sentido oposto, para captar e descrever, na escrita, cada detalhe observado nas audiências. Para chegar ao atual trabalho, foi necessário fazermos um "autoexorcismo" para fins de descrever e lapidar de forma densa os detalhes analisados, de acordo com a definição de Roberto Da Matta (1978, p. 04): 


\begin{abstract}
A segunda transformação parece corresponder ao momento presente, quando a disciplina se volta para a nossa própria sociedade, num movimento semelhante a um autoexorcismo, pois já não se trata mais de depositar no selvagem africano ou melanésico o mundo de práticas primitivas que se deseja objetificar e inventariar, mas de descobri-las em nós, nas nossas instituições, na nossa prática política e religiosa. O problema é, então, o de tirar a capa de membro de uma classe e de um grupo social específico para poder - como etnólogo - estranhar alguma regra social familiar e assim descobrir (ou recolocar, como fazem as crianças quando perguntam os "porquês") o exótico no que está petrificado dentro de nós pela reificação e pelos mecanismos de legitimação.
\end{abstract}

As sociabilidades diferentes influenciam as formas da escrita, que também são diferentes, com a percepção de cacoetes e preconceitos naturalizados na elaboração de peças processuais. Uma reiterada luta de (in)consciência, na busca de descrever os casos de forma minuciosa.

Além dessas questões, no campo do direito há a predominância da escrita focada em "ninguém”, em um sujeito indeterminado, com ações escritas através de verbos impessoais, tais como "conclui-se", "entende-se” etc., ora alternados com verbos em terceira pessoa do plural, como "entendemos", "precluímos" etc., com a finalidade de se falar não em nome de quem escreve, mas em nome de um tido corpo jurídico, em que o "eu" de quem escreve está incluso de forma genérica, calcado em uma doutrina jurídica ou jurisprudência; ou até em nome de "todos", como um meio de universalização do que se escreve, sem responsabilizar o "eu" pela escrita. Grande contraste se faz com a escrita etnográfica, marcada por impressões e reflexões do observador sobre o que ele vê, sobre o que ele observa e descreve. O "eu" do pesquisador em campo constrói os dados, pois ele os observa e os seleciona para sua reflexão. O "eu" do antropólogo arquiteta as reflexões, as relativizações, a sua escrita (LIMA, M., 2017, p. 45). Vale ressaltar que, por se tratar de um artigo em coautoria, o "nós" está muito presente nesse trabalho, mas não com o fim de universalizar nossa escrita, mas de explicitar e demarcar que é uma redação de dois autores explicitamente definidos.

O "campo", no sentido antropológico, se desenrolou aqui em um confronto, evidenciando os riscos epistemológicos, em analisar e reconhecer a validade e os limites do conhecimento em saber lidar com o que o campo traz para o pesquisador. "É um choque de percepções, entre o ponto de vista do pesquisador, com suas verdades, e a forma como ele irá traduzir sua experiência em campo para um texto, para a escrita” (LIMA, M., 2015, p. 43). 


\section{O AMOR NA FAMÍLIA: ENTRE O TRADICIONAL E O ROMÂNTICO}

Neste tópico faremos um debate preliminar sobre o papel do amor, e seus (não) usos, nas audiências observadas nas varas de família e que versam sobre pedido de pensão alimentícia em favor de ex-cônjuge. Questão que será retomada gradualmente em cada tópico a seguir. Analisamos as resoluções das demandas de acordo com as moralidades situacionais apresentadas pelos julgadores em cada caso, considerando a utilização de valores e interesses em cada situação específica (EILBAUM, 2010, p. 374).

Embora o casamento ou a união estável sejam formados, e terminados, por diversos motivos, o amor é um deles. Em que pese o Poder Judiciário estar julgando apenas uma relação jurídica em cada processo, a palavra "amor" aparece de forma recorrente durante duas audiências observadas. A juíza Ana trouxe a ideia de que o fim do casamento é concomitante ao fim do amor, algo tido como automático e intimamente relacionado entre os cônjuges. Assim, faz transparecer uma romantização do instituto do casamento pela operadora do direito através do Poder Judiciário.

A romantização em torno do amor familiar é algo construído socialmente. Na fala dos juízes que conduziram os acordos desses casos surgiu a diferença entre o casamento tradicional e o casamento moderno, ensejando um critério para desigualar as "decisões", ora pautadas num conceito de família tradicional, ora orientadas por um conceito de família moderna.

Conceitualmente, as famílias tradicionais eram formadas por conveniências entre grupos familiares, sem levar em consideração o sentimento e as escolhas das pessoas envolvidas, mas apenas as melhores condições familiares em relação a certos grupos, para melhor acúmulo de bens ou de prestígio social. O clássico conto "Romeu e Julieta", de William Shakespeare (2000), traz o conflito histórico entre duas famílias tradicionais que não aceitam o casamento de Romeu e de Julieta, fundado no amor individual (moderno, romântico), o que revela a tensão entre tradição e modernidade no romance. O suicídio dos protagonistas demonstra que seria impossível a convivência de ambos os modelos familiares num mesmo contexto; um sobrepõe o outro. De forma semelhante, Louis Dumont, na obra Homo Aequalis, traz a comparação por contrastes entre sociedades modernas e sociedades tradicionais, em que 
uma transformação de valores distingue e separa esses dois tipos de sociedade e de conceitos (DUMONT, 2000, p. 19).

O autor constrói um modelo de sociedade holística ou tradicional baseado no modelo de castas da sociedade indiana, em que se valoriza a totalidade social e se subordina o indivíduo ao coletivo, e seus integrantes adquirem sentido e propósito a partir do seu papel social preestabelecido. O todo é mais importante do que a soma dos indivíduos e suas relações puramente pessoais, trazendo o conceito de família tradicional, em que inexiste a opção individual de escolher o parceiro. Os papéis e as motivações de formação da família são anteriormente definidos.

Todavia, as sociedades modernas (ocidentais) são individualistas e igualitárias, os indivíduos têm precedência sobre a sociedade. Nas sociedades modernas há o contratualismo, que resulta em vários contratos entre seus membros, nos quais estão incluídos os casamentos, com o objetivo de conciliar interesses em comum, com um mínimo de igualdade de direitos. O caráter individualista e igualitário permite que nesse formato familiar as pessoas possam escolher com quem casar por diferentes motivos, seja por amor, dinheiro, sexo, amizade ou qualquer outro motivo individual (DUMONT, 2000).

Inicialmente nossa opção teórico-metodológica era analisar os casos observados utilizando a distinção da família tradicional e da família moderna, para identificar a forma usada, alternada, e até mesclada, desses conceitos pelos juízes para conduzir as demandas judiciais e os acordos estudados. Da Matta (1997, p. 190) debate que os dois modelos convivem no Brasil com inúmeros dilemas e paradoxos, pois aqui as leis são igualitárias e modernas, mas a sua aplicação se dá de forma hierárquica nas relações sociais, aplicando-se a lógica tradicional.

As demandas aqui analisadas mesclam os conceitos de família tradicional e amor. O contratualismo (sociedade moderna) dá ensejo a diversos contratos (dentre os quais estão os casamentos e as trocas) entre os membros, tendo em vista interesses em comum, sendo o caráter individualista e igualitário fundado em mecanismos universais de resolução de conflitos pela produção de verdades negociadas. Os indivíduos escolhem com quem devem casar e os motivos que os levam a fazer tal opção. 
Todavia, como mencionado anteriormente, a coexistência dos dois modelos de família no Brasil (DA MATTA, 1997) dificultou identificar a divisão dos casos analisados na dicotomia da família tradicional ou moderna, mas a questão presente na decisão das ações é a seguinte: quando o amor romântico acaba, também põe fim à relação conjugal? Ora, a observação dos casos permitiu identificar a existência de muitas outras questões envolvidas, como a prole, a dependência econômica de um dos cônjuges, a proximidade da residência do casal em relação ao emprego, dentre outros fatores que fazem uma relação conjugal perdurar e que são interpretados, implicitamente, pelos juízes.

\section{3. "VOCÊ ERROU! O AMOR ACABA": O CASO ALDA E JÚLIO}

O “amor" (romântico), e a sua repercussão nos julgados, apareceu de forma mais evidente em duas situações observadas. Tratava-se de uma ação de alimentos entre ex-cônjuges. A separação de Alda e Júlio se deu após vinte e um anos de casados. Era um ex-casal aparentemente de classe média, ambos de pele branca, Alda tinha cinquenta e dois anos na data da audiência, concluiu apenas o primeiro grau do ensino fundamental e não possuía outra fonte de renda. Não foi dita a idade de Júlio, mas não aparentava ter muito mais idade que Alda. Na audiência de conciliação, instrução e julgamento, Júlio foi indagado pela juíza Ana sobre o motivo de Alda nunca ter trabalhado. Ele assim respondeu:

Doutora, na época eu não ganhava muito e achei melhor que ela ficasse em casa para cuidar da nossa filha. O salário que ela conseguia não valia a pena. Ela tentou trabalhar em algumas coisas, mas não deu certo. A decisão de ela largar o trabalho foi nossa.

Durante a fala de Júlio, Alda assente com a cabeça, concordando com o depoimento. No discurso de Júlio há a existência contratual entre as partes, de comum acordo, que decidiram pela necessidade de Alda largar o trabalho remunerado para se dedicar ao cuidado do lar, para cuidar de Marina, filha em comum. A decisão de ambos baseava-se no que era melhor para a família. Júlio preferiu que Alda parasse de trabalhar fora em razão de questões financeiras e, da 
mesma forma, Alda preferiu permanecer cuidando de Marina e se dedicar somente à família, sendo, também, vontade individual de ambos.

Júlio afirma que desde a separação de fato ${ }^{6}$ estava contribuindo com algum dinheiro e com o cartão alimentação em benefício de Alda, mas havia arrumado uma nova esposa e, apesar de essa nova mulher trabalhar fora do âmbito doméstico, seus gastos com a nova família tinham sido majorados. Ademais, o ex-casal não havia chegado a um consenso para assinarem a formalização do divórcio. Júlio informou ter se aposentado, mas ainda permanecia trabalhando em uma empresa privada de grande porte. Nesse momento, a juíza esclareceu poder resolver os dois processos, referindo-se às demandas de alimentos e de divórcio, e posicionou-se da seguinte forma: "por acordo a gente pode tudo".

A audiência transcorreu com o foco no motivo pelo qual a mulher teria abandonado a carreira profissional e se dedicado ao lar e à criação da filha Marina. Diante dessa situação a juíza Ana virou-se para Alda e falou: "Você errou! O amor acaba". Ou seja, diante de contrato feito pelos dois, considerou que o fim do amor (romântico) também daria término às obrigações contraídas. Em seguida, propôs vinte e quatro meses de pensão alimentícia em favor de Alda, mas Júlio retrucou e ofereceu dezoito meses. Alda, nesse momento, afirmou que já havia tentado vender produtos a varejo comercializados por revistas e outros tipos de atividades, tais como refeições ou doces, mas não conseguiu auferir renda suficiente para se manter. Afirma desejar e necessitar da fixação de uma pensão vitalícia para garantir sua subsistência pelo resto da vida.

A magistrada Ana responde que ela e a jurisdicionada Alda possuem quase a mesma idade e afirma ser o mundo dinâmico (traduzimos a palavra "dinâmico" para a presença sutil dos adjetivos moderno, individualista e igualitário, de livre escolha), no qual a pessoa necessita se adaptar. Afirma que a proposta feita é sempre em consonância com o posicionamento do juízo e o valor eventualmente fixado por sentença. Reitera achar razoável o pensionamento por dezoito meses oferecido por Júlio, além de manter vinte e quatro meses de assistência do plano

6 A separação de fato é a livre decisão dos cônjuges de encerrar a sociedade conjugal, porém sem recorrer aos meios legais. A decisão põe fim aos direitos, deveres e efeitos do casamento, mas os cônjuges permanecem no estado civil de casados. Conceito retirado do site do Superior Tribunal de Justiça. Disponível em: <https://www.stj.jus.br/sites/portalp/Paginas/Comunicacao/Noticias/Separacao-de-fato-tambem-permite-cursoda-prescricao-para-pedido-de-partilha-de-

bens.aspx\#: :text=A\%20separa\%C3\% A7\%C3\%A3o\%20de\%20fato\%20\%C3\%A9,no\%20estado\%20civil\%20d e\%20casados>. Acesso em: 07 mar. 2021. 
de saúde, considerando ser a assistência médica ofertada pela empregadora de Júlio, sem qualquer ônus para este.

A juíza Ana discursa que seu entendimento é de não caber pensão vitalícia em favor de uma mulher de cinquenta e dois anos apta a reingressar no mercado de trabalho, considerando, ainda, que a separação do casal de fato já perdurava há quatro anos e a recolocação profissional era pra ter sido realizada. Ana respondeu que diante da situação ali estruturada e do entendimento da magistrada assinaria o acordo nos termos colocados, retrucando da seguinte forma: "Não tem jeito, tudo bem".

A magistrada Ana dá continuidade ao seu discurso e afirma não ser possível manter a obrigação de sustento de Júlio e, caso Alda necessitasse de algum auxílio financeiro, que se socorresse da filha Marina, pessoa com obrigação de auxiliar a mãe financeiramente, desconsiderando a decisão do casal na forma de organização e manutenção do lar, enquanto a prole era incapaz. Marina tinha vinte e quatro anos na data da audiência, trabalhava e ainda fazia faculdade, o que traz a reflexão acerca da independência financeira inexistente neste momento da vida de uma jovem adulta, sendo falado em audiência que Júlio ainda arcava com os custos da faculdade da filha.

É possível perceber o contrato entre o marido e a esposa durante o casamento, diante da comprovação de haver consenso acerca da dinâmica familiar. Enquanto o homem se ocupava do trabalho externo para auferir renda para a família, a mulher mantinha as tarefas domésticas em dia e cuidava da prole em comum, sendo ambas as atividades complementares para a harmonia do lar. Assim, há novamente o choque dos valores tradicionais, gerados como um todo em prol da família, com os valores individualistas, que acabaram se sobrepondo no momento da separação, mediante o tratamento das partes de forma igualitária em relação à subsistência, que merece ser considerada individualmente por Alda e Júlio após o divórcio. Anteriormente, havia um contrato, e o consenso de ambos foi em prol da família em sentido coletivo, mas a juíza Ana aplicou seu entendimento em relação às decisões individuais.

A magistrada Ana entendeu que o seu "saber judicial” (EILBAUM, 2010, p. 361) era baseado na proximidade de sua idade com a de Alda, sem considerar o grau de instrução educacional e de experiência profissional, diferenciado, de ambas, e eventualmente as oportunidades de estudo que de forma notória, em razão do status social que ocupam (uma magistrada e outra dona de casa), foram diferentes nas suas vidas. Além disso, havia o acordo 
entre Alda e Júlio, de que a mulher permaneceria durante toda a união conjugal se ocupando exclusivamente do trabalho doméstico, em troca da manutenção financeira da família pelo marido. Tais moralidades foram aplicadas de forma particular nesta demanda, de acordo com as peculiaridades do caso observado. A juíza aqui entendeu que, com a quebra do contrato de casamento, cada qual deveria seguir seu caminho, separados, inclusive no que tange à dependência financeira da ex-esposa em relação ao ex-marido, algo acordado exclusivamente para os vinte e um anos de casamento, o que fundamentaria, portanto, fechar um acordo de pensão alimentícia por dezoito meses, aquém do pedido demandado pela ex-esposa.

Não há na legislação cível brasileira previsões de como calcular o tempo e o valor das pensões alimentícias para ex-cônjuges, ficando o debate a cargo das doutrinas jurídicas ${ }^{7}$ e dos entendimentos judiciais, de primeira e segunda instância ${ }^{8}$. Na doutrina jurídica, é comum o entendimento de que os "alimentos transitórios" derivam do princípio da igualdade jurídica entre gêneros, atribuindo, em especial, a emancipação da mulher à sua atual e crescente inclusão no mercado de trabalho (MADALENO, 2014, p. 933), além do princípio da liberdade, em que os cônjuges são livres para se escolherem, assim como seus modos de viver no casamento, inclusive abdicar-se do trabalho remunerado, sendo estas consideradas concepções modernas do direito brasileiro. Assim, esse seria um modelo moderno de pensão à ex-cônjuge.

Em contraponto, a pensão alimentícia vitalícia, no discurso doutrinário jurídico, é aquela nos moldes "tradicionais" que remontaria aos tempos de desigualdade material entre homens e mulheres, ou seja, nesse modelo tradicional, ao ex-marido caberia sustentar financeiramente sua ex-esposa por tempo indefinido. Nesse discurso, as pensões transitórias seriam a regra, e a pensão vitalícia seria a exceção, para "não fomentar o ócio e o parasitismo" pelo ex-cônjuge (DIAS, 2013, p. 105). No caso observado de Alda, aplicou-se um modelo "moderno" de pensão alimentícia, para um modelo moderno de família (calcado no amor romântico e na livre escolha de papéis entre os cônjuges), embora a demandante de pensão nunca tenha ingressado no mercado de trabalho e não possuísse fontes de renda aos seus cinquenta e dois anos de idade

\footnotetext{
${ }^{7}$ Nesse sentido, veja, por exemplo: BUZZI, Marco Aurélio Gastaldi. Alimentos transitórios, uma obrigação por tempo certo. Curitiba: Juruá, 2003. p. 123; MADALENO, Rolf. Curso de Direito de Família, 5. ed., Rio de Janeiro: Editora Forense. 2014. p. 993; DIAS, Maria Berenice. Alimentos aos Bocados. São Paulo: Editora Revista dos Tribunais, 2013, p. 105.

${ }^{8}$ Veja, por exemplo, STJ - REsp: 1608413 MG 2014/0108027-8:

"Não se deve fomentar a ociosidade ou estimular o parasitismo nas relações entre ex-cônjuges, principalmente quando, no tempo da separação, há plena possibilidade de que a beneficiária dos alimentos assuma, em algum momento, a responsabilidade sobre seu destino, evitando o prolongamento indefinido da situação de dependência econômica de quem já deixou de fazer parte de sua vida".
} 
(requisitos de aplicação da pensão alimentícia moderna no discurso jurídico), contrariando, portanto, entendimentos doutrinários e jurisprudenciais sobre a questão.

\section{A TROCA DE FAVORES: O CASO CRISTINA E DÉLCIO}

No mesmo dia da audiência de Alda e Júlia, foi possível assistir a outra audiência sobre o mesmo assunto, alimentos em favor de ex-cônjuge. A juíza Ana acumulava a Vara de Família que ficava do lado oposto do corredor e realizava as audiências na companhia de outra promotora de justiça, Ariel.

O julgamento desta vez tinha como partes Cristina e Délcio. Cristina tinha uma forte presença, entrou toda maquiada, com um vestido nitidamente escolhido de forma pontual para a ocasião e cabelos feitos, mas seguiu de forma desvairada, como se estivesse atordoada, encaminhando-se para dentro do cartório. A juíza Ana, com um semblante surpreso, chamou-a em tom alto para que ela voltasse para a sala de audiência, momento em que Cristina se orientou no ambiente e conseguiu sentar à mesa de audiência para iniciar o ato judicial. Ambos tinham a pele de cor branca, Délcio aparentava ser bem mais velho do que a ex-esposa, cabelos lisos, que chegavam aos seus óculos aparentemente bem antigos, roupas bem usadas e mancava de uma perna, uma aparência frágil, diante de uma magreza bem peculiar.

O casal permaneceu casado de 1983 até setembro de 2019, em um total de trinta e seis anos. A relação era constituída, segundo ambos, apenas por uma troca de favores há vinte anos - viviam separados de fato. Enquanto ele mantinha a casa, provendo os valores suficientes para pagar a totalidade das contas da residência, Cristina se ocupava dos serviços domésticos atinentes à residência e demais serviços em relação ao filho em comum, com trinta e cinco anos de idade atualmente.

A fala das partes demonstrava a existência de um contrato, um acordo realizado entre eles, com divisão de trabalho tradicional e papéis complementares. Enquanto a mulher se ocupa das tarefas domésticas, o homem cuida do sustento da família, de forma integral. Inexiste a presença do discurso do amor neste julgamento; em nenhum momento os sentimentos românticos apareceram nas falas. 
Nos fins de semana Délcio ia até a casa de Tereza, sua concubina. Juntos, o casal teve uma filha de nome Nádia, atualmente com vinte e sete anos de idade. Na residência de Tereza, também era Délcio o responsável por arcar com as despesas de manutenção da casa. Ficou claro na audiência ser de conhecimento de Cristina e de Tereza a vida dividida de Délcio e todas as responsabilidades decorrentes dessa decisão.

Em razão da localização do seu emprego, Délcio ficava de segunda até sexta-feira na residência de Cristina e nos fins de semana permanecia na companhia de Tereza, local mais distante da sua atividade laborativa. Com a aposentadoria, Délcio fez sua escolha definitiva e rompeu o pacto realizado com Cristina, se separou dela e se mudou definitivamente para a casa de Tereza, motivo pelo qual a ação de alimentos foi ajuizada por Cristina, diante do inadimplemento das despesas da residência.

Cristina tinha sessenta anos de idade na data da audiência e informou receber um valor referente a um imóvel alugado exclusivamente dela e do seu irmão. Em conjunto com seu irmão Vitor, possuíam um apartamento que gerava renda no valor de seiscentos reais mensais somente para Cristina. O acordo entre Délcio e Cristina estava difícil em razão de uma diferença de cem reais entre as propostas. Neste momento, inexistiu qualquer discussão acerca de não haver o pensionamento vitalício, sendo natural e certo para as partes ali presentes.

Enquanto Délcio queria pensionar no valor de seiscentos reais, Cristina exigia a pensão no patamar de setecentos reais. Diante da situação, a magistrada Ana se pronunciou: “Olha só! São quarenta anos de casados". Nesta fala a intervenção desconsiderou o período de vinte anos de separação de fato. Em seguida, ainda complementou:

\footnotetext{
Em termos de valores, esse percentual fica em torno de $20 \%$ da sua aposentadoria. Não é nada demais, ainda mais se considerarmos que vocês estão numa idade que não dá nem para se cogitar num pensionamento temporário.
}

Após essa intervenção do juízo, o acordo foi assinado no montante de seiscentos e cinquenta reais de pensionamento vitalício em favor da mulher. A diferença discutida para realizar o acordo no patamar de cinquenta reais se mostra insignificante quando contextualizada com o padrão de vida apresentado pelo ex-casal. Délcio manteve duas casas durante pelo menos 
vinte e sete anos (idade de sua filha com Tereza), e Cristina recebe um aluguel, além de ter ficado com a sua residência e os bens que a guarneciam. Portanto, a deficiência monetária de cinquenta reais em debate seria somente para traduzir um insulto moral presente naquele conflito familiar.

A juíza Ana traduziu os insultos morais preexistentes na relação, a validação, o reconhecimento necessário pelas partes e as demandas morais em um valor monetário intermediário, a fim de que ambos pudessem se sentir satisfeitos e cedendo sem ser na totalidade, para que estivessem aptos a finalizar um acordo. Nesse caso, a magistrada sequer citou a existência ou não de amor, como no caso de Alda e Júlio, mas conduziu o acordo para que Cristina recebesse uma pensão vitalícia de Délcio. Não foi possível identificar algum critério norteador explícito que trouxesse uma lógica moral condutora para ambos os casos. Apenas a diferença de idade (oito anos) entre as mulheres e o pacto aberto de duas relações simultâneas no caso de Cristina, sabedora há mais de vinte anos da existência da outra família de Délcio e que, mesmo assim, concordou em manter os serviços domésticos em troca de garantir sua subsistência. Ademais, Cristina ainda era proprietária de um imóvel exclusivamente seu e de seu irmão, o que lhe garantia uma renda extra, além da pensão.

Tanto o casamento de Alda e Júlio quanto o de Cristina e Délcio se deram nos moldes modernos das relações sociais, da livre escolha de papéis, mas tiveram diferentes desfechos. No primeiro, a pensão alimentícia seguiu um entendimento moderno (sem manutenção do status quo e dos papéis assumidos no casamento. Cada qual deveria seguir novos caminhos, separados), enquanto no segundo caso o raciocínio se deu como algo tradicional (manutenção do status quo e dos papéis econômicos assumidos durante o casamento). O que os diferenciou, fundamentalmente, foi a presença ou não de "amor". O amor e a dedicação à família foram considerados como algo não merecedor de uma pensão vitalícia diante da ausência de consciência de Alda em não identificar que cada indivíduo responde por si e pela sua própria subsistência de forma individual, tendo em vista a insegurança e a possibilidade de finalização das relações pessoais (o acordo entre as partes de divisão de tarefas durante o casamento foi nos moldes da família tradicional, e a moral da juíza aplicou o pensamento relacionado à individualidade, relacionada à família moderna).

A condução dos acordos em situações semelhantes de forma diferente pela mesma juíza demonstra a aplicação individualizada dos valores morais nos casos, sem considerá-los como 
uma unidade ou imutáveis, mas aplicados em cada situação e de acordo com os envolvidos (EILBAUM, 2010, p. 23), trazendo, portanto, insegurança jurídica.

\section{5. "JÁ DESCANSOU BASTANTE": O CASO RITA E CÉSAR}

O terceiro caso de pensão alimentícia em favor de ex-cônjuge foi julgado pela juíza Olga, em vara de família diversa. Não foi possível ver Rita e César pessoalmente, ainda que a audiência tenha ocorrido na tela do computador. Foi a primeira audiência virtual observada, sendo permitido acompanhar apenas a dinâmica do ato processual a distância da mesa da juíza Olga. Deste modo, só houve a possibilidade de se ouvir a audiência. A união conjugal perdurou por vinte e três anos. Celso era Advogado Geral da União e Rita se dedicou à criação dos filhos. João, o mais velho, contava com vinte e três anos de idade e Melissa tinha onze anos.

Mais uma vez houve a existência de papéis complementares dentro do acordo pactuado entre o casal. A decisão provisória de alimentos fixava dez por cento da remuneração em favor de Rita e vinte por cento em favor de Melissa, filha em comum do casal. A pensão do filho mais velho não estava sendo discutida nesta demanda.

Durante a audiência foi falado que Rita trabalhou em dois momentos durante a convivência do casal, por um ano e meio vários anos antes e, em 2019, por dois meses, como contratada em uma secretaria estadual. Não foi falada a idade de Rita e, perguntada pelo juízo por quanto tempo ela achava que conseguiria se recolocar no mercado de trabalho, respondeu que acreditava demorar cerca de cinco anos, diante do difícil contexto econômico agravado pela pandemia.

A pergunta da juíza Olga traz um discurso de moralidade moderna, considerando cada pessoa que antes formava o ex-casal de forma individual. A proposta de pensionamento em favor de Rita, elaborada pela promotora de justiça Kátia e acolhida pela magistrada Olga, apresentava uma retirada gradual da pensão para a ex-cônjuge de forma que a realidade de ambos fosse se adequando aos novos valores mensais auferidos. $\mathrm{O}$ alimentante negou fazer qualquer acordo, e a juíza advertiu: 


\begin{abstract}
A proposta do juízo é tecnicamente a melhor para o seu cliente, estamos no meio de uma pandemia. Depois já retira direto a pensão da mulher. É uma proposta bastante ponderada, sendo o período de maturação da separação. Doutor, seu cliente pagaria durante um ano dez por cento para a mulher, no segundo ano oito por cento e no terceiro ano seis por cento.
\end{abstract}

A juíza Olga, durante a audiência, quando indagada pelo advogado de Rita sobre o percentual gradual de retirada da pensão alimentícia, no sentido de manter o valor de dez por cento em todo o período de três anos de pensionamento, faz um comentário que coloca parte das moralidades naturalizadas em relação ao trabalho doméstico da mulher, mencionando que o serviço no lar é uma forma de descanso: "Já está na hora de ela trabalhar, a menina tem onze anos já. Já descansou bastante. Vão fechar o acordo ou não?".

Nesse discurso da juíza Olga, a dedicação exclusiva de Rita ao trabalho doméstico durante a união conjugal é sinônimo de descanso. Neste caso, a moralidade apresentada no discurso traduz um pensamento naturalizado da julgadora em que a dedicação aos filhos não foi reconhecida como sendo algo fundamental na organização da família, e assim ainda deixou de reconhecer a importância do trabalho. A presença de amor na relação conjugal também não foi sequer discutida.

O exercício exclusivo da maternidade, neste caso, é tratado de forma hierarquizante, se comparado com a atividade laborativa exercida por Celso como Advogado Geral da União, considerando a categoria nos termos do conceito de honra (LIMA, K., 2013, p. 551), na medida em que as pessoas não são tratadas da mesma forma pelo Poder Judiciário. É notório o valor que uma família deve despender quando necessita contratar uma babá para se ocupar dos cuidados dos filhos e, no mínimo, uma empregada doméstica para manter a organização, limpeza e manutenção das refeições para os indivíduos da família.

Através de simples consulta a alguns sites especializados no trabalho doméstico, constatei os salários mínimos referentes ao trabalho de uma empregada doméstica e de uma babá no Estado do Rio de Janeiro, sendo, respectivamente, $\mathrm{R} \$ 1.237,15^{9}$ e $\mathrm{R} \$ 1.174,83^{10}$. Portanto, considerando a necessidade de o Poder Judiciário, através dos operadores do direito,

9 Salário Mínimo de Empregada Doméstica 2021. Disponível em: <https://www.idomestica.com/tabelas/salario-empregada-domestica>. Acesso em: 20/mar/2021. 10 Baba - Salário 2021 - Rio de Janeiro, RJ - Mercado de Trabalho. Disponível em: <https://www.salario.com.br/profissao/baba-cbo-516205/rio-de-janeiro-rj/>. Acesso em: 20/mar/2021. 
quantificar as demandas morais e transformá-las em pecúnia, uma mulher que durante o casamento exerce exclusivamente os trabalhos domésticos acumulando as duas funções (de babá e empregada doméstica) economiza para a família a soma desses dois valores anteriormente indicados, o que também poderia ser tomado como contribuição pecuniária em prol do núcleo familiar, mas diante da moralidade aplicada neste terceiro caso de pensão em favor de ex-cônjuge não foi levado em conta, mas a moral naturalizada da juíza Olga vislumbrou como um período de descanso, permanecendo o trabalho invisibilizado.

\section{6. "CADA CASO É UM CASO": AS ENTREVISTAS}

Com relação aos critérios para fixar a pensão e as moralidades situacionais, há entrevistas abertas com dois magistrados de Varas de Família do Estado do Rio de Janeiro, em que foi perguntado como eles decidiam esses tipos de conflito. O juiz Renan afirmou serem "casos e casos", no sentido de que é necessária a interpretação do juiz para proferir a decisão ou o acordo. O magistrado dá exemplo de um caso que julgou de uma mulher muito idosa, com noventa anos de idade, e que se divorciou, motivo pelo qual pleiteou pensão vitalícia, mas somente possuía seis anos de casamento. O juiz Renan afirma não ser possível fixar uma pensão que seria devida por um período maior do que o período do casamento, demonstrando ser este um critério para suas decisões.

O magistrado afirma ser muito adotado por colegas juízes esse critério da idade da mulher para concessão de pensão vitalícia e que, inclusive, para ele, cinquenta anos já é uma idade considerada alta para uma mulher (re)ingressar no mercado de trabalho. Porém, apesar desse discurso, ele também diz que o caso da idosa de noventa anos é uma exceção, pois, embora ela não esteja apta ao mercado de trabalho, o tempo de convivência do casal foi muito exíguo e não permitiria a fixação de pensão vitalícia.

O discurso do magistrado Renan aponta critérios para concessão da pensão alimentícia como a idade e o tempo de casamento, mas também afirma depender do caso, ratificando a observação das moralidades situacionais aplicadas pelos julgadores de forma casuística, em oposição à segurança jurídica. Ao mesmo tempo em que há um discurso de critério para medir tempo e valor de pensão, o da idade da demandante, surge o "depende do caso". 
Outro magistrado entrevistado, Leonardo, afirma que a culpa de o Judidicário não conseguir resolver as questões de lide familiar é das pessoas, pois há uma cultura litigante na sociedade brasileira. E é, justamente, por isso que ele precisa resolver tudo. Para tanto, ele dispõe que possui uma visão do conjunto da família em cada caso, proporcionando a ele um olhar para além das visões civilistas (Código Civil) e patrimoniais (dinheiro). Para ele, "se uma pessoa é anulada pelo casamento e não tem chance de se manter sozinha financeiramente, é para ter pensão vitalícia”. Não há qualquer menção quanto ao critério da idade, mas ao citar o caso de Alda - descrito anteriormente neste trabalho -, que não conseguiu pensão vitalícia aos cinquenta e dois anos de idade, mesmo com vinte e seis anos de casamento, o juiz Leonardo fez uma intervenção ratificando o indeferimento da pensão vitalícia. Ele afirmou haver um entendimento consensualizado sobre a idade da ex-mulher, mas, novamente, traz no discurso a frase “cada caso é um caso", sendo uma análise, portanto, situacional.

Embora ambos os juízes trouxessem em seus discursos que há um consenso dos magistrados em relação à idade em que é devida a pensão vitalícia, o juiz Renan entende ser cinquenta anos uma idade apta a justificar a pensão vitalícia em favor do cônjuge, mas o juiz Leonardo e a juíza Ana entendem ser a idade de cinquenta anos apta ao ingresso no mercado de trabalho, o que demonstra inexistir o alegado consenso, acarretando, consequentemente, insegurança jurídica. Há uma clara dissonância entre tipos ideais e práticas.

Essas entrevistas corroboram a ideia aqui observada acerca da aplicação de critérios variados e implícitos - às partes, à lei e à doutrina jurídica - nos seus julgamentos, orientados por moralidades situacionais, as quais são expostas e aplicadas pelos magistrados, dependendo do contexto, das situações e das pessoas envolvidas, o que viola a segurança jurídica diante da imprevisibilidade das decisões.

\section{OS ACORDOS: ENTRE MORALIDADES E (IM)PARCIALIDADE}

No caso de Cristina e Délcio, a mulher se dedicou ao serviço do lar sabendo que o marido possuía outra família e teve seu acordo conduzido para receber a pensão vitalícia. Assim, o trabalho doméstico exercido durante a união conjugal foi reconhecido na mesma medida em que o trabalho exercido fora do lar por Délcio. 
Nos casos analisados, foi possível perceber a condução das juízas de forma a realizar os acordos entre as partes dependendo de cada contexto fático, em hipóteses de casais nos quais as mulheres se dedicaram apenas ao serviço doméstico, tornando a moralidade adaptável às situações concretas. Consequentemente, dependendo da situação em análise, há o reconhecimento ou a desconsideração da identidade a ser buscada na demanda judicial (CARDOSO DE OLIVEIRA, 2004, p. 11), mas sem saber os critérios explícitos para tal.

Quando a magistrada Ana fala para a jurisdicionada Alda sobre ela ter feito a opção errada por apenas se dedicar às tarefas não remuneradas do lar, pois o amor acaba, trouxe uma posição pessoal moral, naturalizada e expressa nesta afirmação. A autoridade judicial tinha conhecimento de que a mulher não possuía renda para manter a própria subsistência e a separação de fato havia ocorrido há quatro anos; neste caso, negou o pensionamento vitalício, mas no segundo caso analisado (ex-casal Cristina e Délcio), a relação conjugal não mais existia entre as partes há vinte anos, até o momento em que Délcio resolveu sair definitivamente da residência. Cristina recebia um valor mensal referente a um imóvel locado por ela, mas contava com oito anos a mais de idade do que Alda. Diante disso, os casos são bem semelhantes, mas ensejaram conclusões diferentes do juízo.

No terceiro caso (ex-casal Rita e Celso) não foi debatido em audiência o período de separação de fato das partes e o motivo pelo qual Rita não se dedicou a uma carreira profissional fora do âmbito doméstico e permaneceu dedicada à maternidade, motivo pelo qual não podemos aplicar a comparação em relação aos demais casos deste tópico.

Portanto, quanto aos dois primeiros casos, apesar de serem semelhantes, tiveram resultados diferentes; o principal diferencial era Cristina possuir oito anos a mais que Alda e a relação conjugal formal (período constante na certidão de casamento, sem considerar o período da separação de fato) ser mais longa, requisitos estes que pareceram determinantes para formar a convicção da julgadora na aplicação da moralidade situacional. Os casos são semelhantes, mas o resultado foi diferente. A mesma lógica da relação longa foi aplicada de forma diversa, fomentando insegurança jurídica.

Pela comparação entre os casos, causa estranheza perceber que dois casos semelhantes julgados pela mesma juíza tiveram soluções diversas. A magistrada Ana conduziu o desfecho da demanda com afirmações morais contrárias de situações parecidas. Não foi possível identificar o reconhecimento da identidade atribuída à maternidade perante esses casos julgados 
pelo Poder Judiciário. No primeiro (Alda e Júlio), o trabalho doméstico da mulher foi desconsiderado, mas no segundo (Cristina e Délcio) a magistrada Ana atribuiu a questão do tempo de casados e os serviços do lar prestados como sendo determinantes para a formação do seu convencimento, a fim de ensejar eventual pensão vitalícia, atribuindo valor aos cuidados com a prole e com a casa na divisão das tarefas necessárias para manutenção de um lar. No terceiro caso (Rita e Celso), a juíza Olga não reconheceu qualquer relevância do serviço doméstico, caracterizando-o como um período de descanso.

Outrossim, foi dito que Alda apenas propôs a demanda após o falecimento de uma tia. Durante a audiência foi relatado que, desde a separação de fato, Alda se ocupava em cuidar de uma tia que morava com o casal desde a constância do casamento e possuía uma pensão que garantia a subsistência das duas. Apenas com o falecimento dessa tia e a impossibilidade de se manter (que era do conhecimento de Júlio), Alda entendeu ser necessário propor a demanda de alimentos.

A honra é subjetiva e hierarquizante, sendo atribuída a grupos de pessoas, mas a dignidade é universalizante, característica conferida a todos. No caso de Alda e Júlio a maternidade foi utilizada como categoria hierarquizante, ligada à honra, no sentido de que a opção da família para que Alda se dedicasse apenas ao trabalho doméstico levou ao não reconhecimento da pensão vitalícia.

No Brasil, há uma alternância da honra e da dignidade, uma coexistência das duas. Na legislação pátria ambas são garantidas pela Constituição da República, sendo o direito fundamental à honra indicado no artigo $5^{\circ}$, inciso $\mathrm{X}$, e a dignidade da pessoa humana, um fundamento do Estado Democrático de Direito, conforme artigo $1^{\circ}$, inciso III ${ }^{11}$.

\footnotetext{
11 Art. $1^{\text {o: }}$ A República Federativa do Brasil, formada pela união indissolúvel dos Estados e Municípios e do Distrito Federal, constitui-se em Estado Democrático de Direito e tem como fundamentos:

I - a soberania;

II - a cidadania;

III - a dignidade da pessoa humana;

IV - os valores sociais do trabalho e da livre iniciativa; (Vide Lei $n^{\circ} 13.874$, de 2019)

V - o pluralismo político.

Art. $5^{\circ}$ Todos são iguais perante a lei, sem distinção de qualquer natureza, garantindo-se aos brasileiros e aos estrangeiros residentes no País a inviolabilidade do direito à vida, à liberdade, à igualdade, à segurança e à propriedade, nos termos seguintes: (...)

$\mathrm{X}$ - são invioláveis a intimidade, a vida privada, a honra e a imagem das pessoas, assegurado o direito a indenização pelo dano material ou moral decorrente de sua violação.
} 
O conceito de honra nos reporta, novamente, a uma concepção estamental da estrutura social, na qual a desigualdade jurídica, e a honra distribui-se desigualmente sobre seus membros, diferentemente do conceito de dignidade, que se aplica a todos os cidadãos de maneira uniforme. (LIMA, Kant, 2013, p. 556)

A maternidade foi atribuída à dignidade como categoria universalizante no caso de Cristina e Délcio, diante do contrato feito pelo casal, no sentido de que o trabalho doméstico da mulher/esposa seria remunerado com o pagamento das contas da residência do ex-casal, sendo do conhecimento de todos que havia duas famílias, e a opção de Délcio em permanecer na residência em que era casado com Cristina se dava por questões de logística, para comparecer ao trabalho diariamente de modo menos cansativo.

Em todos os três casos, os maridos propuseram os divórcios, as mulheres, as ações de alimentos, e as juízas encaminharam o acordo de forma distinta. O primeiro e o segundo caso foram julgados pela mesma magistrada Ana, e o terceiro, por magistrada diversa, Olga. Ademais, quando a magistrada Ana usa a fala "o amor acaba", demonstra o seu convencimento em relação à demanda. Há uma naturalização da maternidade como forma de opressão e supressão de direitos diante da ausência de reconhecimento e, assim, remete à honra.

Se a igualdade cidadã implica sempre um equilíbrio entre direitos e status como símbolo de igualdade, conforme sensibilidades cívicas locais, a regra proposta por Barbosa sugere uma forma de "tratamento igualitário" na qual os direitos seriam diferenciados (ou desigualados) de acordo com o status do cidadão. (CARDOSO de OLIVEIRA, 2018, p. 40)

No segundo caso descrito (de Cristina e Délcio), em mais da metade dos trinta e seis anos de casados havia apenas um acordo, um casamento "contratual" para fins de manutenção da subsistência da mulher, melhor organização da rotina doméstica e pelo fato de o imóvel ser mais próximo do trabalho de Délcio. Todavia, a visão da magistrada foi universalizante, equiparando os gêneros e reconhecendo o contrato realizado entre as partes como apto a ser reconhecido e a viabilizar a pensão alimentícia vitalícia.

Deste modo, diferentes indivíduos teriam iguais direitos diante do Estado para justificar moralmente a desigualdade que o mercado impõe. Tal pensamento relativo à igualdade deixa 
de lado a concepção de que os semelhantes eram dotados dos mesmos privilégios, no exato momento em que os diferentes em tal parâmetro eram desiguais juridicamente. Roberto Kant de Lima discorre que, no ordenamento jurídico brasileiro, ambos os parâmetros - da honra e da dignidade - estão vigentes (LIMA, Kant, 2013, p. 551). O tratamento desigual do Poder Judiciário em relação às demandas julgadas traduz uma ordem fundante. Trago a lição de Roberto Kant de Lima nesse sentido:

\begin{abstract}
o "outro" cidadão, se for diferente, está fadado a receber tratamento jurídico (leia-se policial e judicial) desigual. (...) A obediência às regras, como tenho apontado sistematicamente em meus trabalhos (LIMA, Kant, 2008), toma valoração negativa, de obediência subalterna, e a sua desobediência pode até ser ilegal, mas não se afigura como imoral. (LIMA, Kant, 2013, p. 554)
\end{abstract}

Se a aplicação da lei fosse uniforme, os "processos de normalização da sociedade" (LIMA, Kant, 2013, p. 555) seriam favorecidos, mas o tratamento desigualador gera dependência em relação às circunstâncias externas de controle. As demandas analisadas no presente trabalho trazem de forma implícita a busca por reconhecimento de identidades, em especial de uma identidade frequentemente invisibilizada nos afazeres domésticos e no exercício da maternidade.

Para as partes, ajuizar uma demanda judicial tem a ideia de validação dos pleitos pelo Poder Judiciário, com a respectiva busca pela sensação de reconhecimento. Observamos algumas partes chorando, apreensivas e até mesmo com uma aparência emocionalmente desestabilizada diante da situação a que ficam expostas no tribunal.

Não obstante, a revolta dos atores frente à experiência do insulto é recorrente e expressa em depoimentos, comentários, reações discursivas e manifestações de indignação diversas, onde percepção e emoção costumam estar fortemente associadas, como dois lados da mesma moeda. A relação entre a dignidade, identidade e sentimentos indica a importância da alteridade ou do caráter dialógico do reconhecimento, que não pode ser expresso adequadamente no plano exclusivamente formal. (CARDOSO DE OLIVEIRA, 2004, p. 02) 
No julgado de Cristina, em que a esposa é reconhecida enquanto sujeito de direito para receber a pensão vitalícia por ter se dedicado ao trabalho doméstico durante quase quarenta anos (ainda que soubesse da diversificação de afeto que fazia o marido manter outra família), percebemos a concessão da efetiva visibilidade pelo Poder Judiciário ao insulto moral, através da proposta de acordo feita pela autoridade competente. Em um momento da discussão entre as partes, Cristina afirma: "Você combinou que manteria a casa", trazendo o acordo verbal feito pelo casal. O contrato por eles praticado foi relevante na condução do caso.

As partes vão ao Poder Judiciário para manifestar emoções de conteúdo moral, sendo a demanda meio de formalização do ato para facilitar de maneira adequada a transmissão da necessidade e converter em valores monetários os insultos, bem como o reconhecimento.

A fala das partes em relação aos sentimentos que levam à propositura da ação é para possivelmente equacionar conflitos derivados de insultos. Quando a autoridade que representa o Poder Judiciário desiguala os jurisdicionados, salta aos olhos a rejeição de identidade da parte com atos de desconsideração que caracterizam a percepção do insulto. Quem recusa a dádiva não se orienta a fim de ganhar, mas "desconhece a identidade do interlocutor" (CARDOSO DE OLIVEIRA, 2004, p. 5).

Os juízes fazem um trabalho pedagógico no sentido de trazer seus preconceitos nativos em relação a ser mãe, ser pai, ser esposa, ser marido, sobre o amor, o trabalho e a remuneração. Não é um valor moral exclusivo das juízas observadas, mas também são valores morais socialmente difundidos. Porém, no caso dos magistrados há uma pseudoneutralidade nesses preconceitos por meio dos princípios jurídicos da imparcialidade e do livre convencimento motivado do juiz (MENDES, 2012; LUPETTI, 2013). Embora a sociedade, em razão de uma moral dominante, também diga o que é ser mãe, ser pai e afirmar que é necessário ter amor no casamento, essa moralidade é aplicada de forma situacional nas audiências judiciais e, por isso, depende do caso a ser julgado e das pessoas envolvidas. 


\section{CONSIDERAÇÕES FINAIS}

Diante de tudo que foi explicitado no decorrer deste trabalho, debatemos serem os conflitos de natureza familiar algo maior do que os processos judicializados, na medida em que transcendem a burocracia e o rito processual. O Poder Judiciário tem acesso apenas a um lapso temporal bem reduzido desses conflitos, se compararmos com a expectativa de vida das partes, sendo que em alguns casos tais conflitos se eternizam na vida das partes envolvidas diante da proximidade dessas relações. O termo nativo "o amor acaba" foi ouvido por nós durante uma audiência, e o sentimento "amor" estava presente em muitos momentos durante a pesquisa de campo, nas audiências.

Os magistrados observados trazem a necessidade de o amor acabar para que os casamentos terminem de forma concomitante, bem como carregam, ainda que de forma silenciosa, o amor parental para as ações de alimentos em favor de filhos menores. Ocorre que o amor é apenas parte dessas relações familistas. A manutenção dos vínculos familiares nem sempre permanece pelo amor, mas tais vínculos podem manter-se por anos, em razão de outras questões, como a amizade, o sexo, o patrimônio, as relações de parentesco ou até mesmo o mero comodismo.

Os múltiplos conflitos presentes no Poder Judiciário precisam ser entendidos pelos operadores do direito para que sejam absorvidos e decididos. As identidades devem ser reconhecidas e compartimentadas, a fim de que as partes possam exercer os papéis esperados socialmente. Uma ação judicial que envolve uma união desfeita, em algumas hipóteses há violência e o desejo de uma divisão quanto às responsabilidades e às obrigações em relação aos filhos. Os insultos morais presentes nas ações são unicamente traduzidos em valores monetários para encontrar uma solução judicial.

As mulheres buscam o reconhecimento de suas demandas quando se sentem legitimadas a ingressar judicialmente, para obterem as respostas ao insulto moral sofrido, os quais algumas vezes não encontram respaldo no Poder Judiciário quando, por exemplo, a magistrada Ana entendeu a decisão conjunta do casal, de a mulher se dedicar apenas à prole durante mais de trinta anos de casamento, como um erro individual, ainda que tenha sido confirmado na audiência que foi algo acordado durante a união conjugal. 
Nas entrevistas realizadas com os magistrados, em que pesem fixarem alguns critérios norteadores das decisões como a idade dos envolvidos e o tempo de casamento, ao final das falas a frase que mais ouvimos foi a de que "cada caso é um caso", deixando as decisões abertas a um número incontável de possibilidades de decisões, sempre a cargo do casuísmo e da moral que os magistrados vislumbram estar sendo debatida no caso.

As justificativas para a condução dos acordos em nenhum momento foi a previsão legal ou a sujeição a um direito legalmente previsto, mas sim devido aos entendimentos de haver a possibilidade ou a impossibilidade de eventual merecimento do provimento jurisdicional pelas partes, através da análise moral da situação, que é capaz de determinar se o indivíduo merece ser privilegiado com a decisão ou não.

A honra e a dignidade também apareceram nos casos analisados como forma de hierarquizar ou universalizar as consequências das decisões. Dependendo do contexto e, ao que nos pareceu, do pensamento momentâneo do julgador, demonstrando a desigualdade de gênero, com a concessão de tratamento hierarquizante e, em outra demanda, por exemplo, no caso de Cristina e Délcio, ele aplicou a dignidade, universalista, sendo certo que o contrato entre as partes foi considerado a fim de conceder tratamento igualitário entre o casal.

Os casos observados demonstram magistrados com diversas perspectivas morais sem que existam critérios específicos aptos para orientar os resultados a serem esperados pelos jurisdicionados. A mesma moral anteriormente definida por um magistrado pode ensejar conclusões diversas em outros casos, ainda que as situações sejam bem semelhantes. As decisões dependem das circunstâncias analisadas e do merecimento que os magistrados entendem haver na ação específica, acabando por gerar insegurança jurídica, o que contraria o princípio da segurança jurídica, previsto na Constituição da República de 1988, nos termos do art. $5^{\circ}$, inciso XXXVI.

\section{REFERÊNCIAS BIBLIOGRÁFICAS}

Ato Normativo Conjunto $\mathrm{n}^{\mathrm{o}} 25$ regulamenta Plano de Retorno programado às Atividades Presenciais do TJRJ. Disponível em: <http://www.tjrj.jus.br/noticias/noticia/-/visualizarconteudo/5111210/7305558>. Acesso em: 20 mar. 2021. 
Babá - Salário 2021 - Rio de Janeiro, RJ - Mercado de Trabalho. Disponível em: $<$ https://www.salario.com.br/profissao/baba-cbo-516205/rio-de-janeiro-rj/>. Acesso em: 20 mar. 2021.

BAPTISTA, Bárbara Gomes Lupetti. Paradoxos e Ambiguidades da Imparcialidade Judicial: entre "quereres" e "poderes". Porto Alegre: Sergio Antonio Fabris, 2013.

BUZZI, Marco Aurélio Gastaldi. Alimentos transitórios, uma obrigação por tempo certo. Curitiba: Juruá, 2003.

CARDOSO DE OLIVEIRA, Luís Roberto. Honra, Dignidade e Reciprocidade. Série Antropologia. A nova ordem social: perspectivas da solidariedade contemporânea. Rio de Janeiro: Vozes, 2004. 63, 2018.

Sensibilidade cívica e cidadania no Brasil. Revista Antropolítica, n. 44, Niterói, p. 34-

DA MATTA, Roberto. Carnavais, Malandros e Heróis: Para uma sociologia do dilema brasileiro. 6. ed. Rio de Janeiro: Rocco, 1997.

O Ofício do Etnólogo ou como ter "Anthropological Blues". In: NUNES, Edson de Oliveira (org.). A aventura sociológica: Objetividade, paixão, improviso e método na pesquisa social. Rio de Janeiro: Zahar, 1978.

DI PIETRO. Maria Sylvia Zanella. O STJ e o princípio da segurança jurídica. Disponível em: https://migalhas.uol.com.br/depeso/302189/o-stj-e-o-principio-da-seguranca-juridica. Acesso em: 25 fev. 2021.

DIAS, Maria Berenice. Alimentos aos Bocados. São Paulo: Editora Revista dos Tribunais, 2013.

DUMONT, Louis. Homo Aequalis. São Paulo: EDUSC, 2000.

EILBAUM, Lucía. “O bairro fala”: conflitos, moralidades e justiça no conurbano bonaerense. Universidade Federal Fluminense: Niterói, 2000.

FREIRE, Marcella do Amparo Monteiro. "O Amor Acaba": um estudo sobre as moralidades aplicadas na prática das varas de família. Dissertação (mestrado em Direito) - Programa de PósGraduação em Direito, Universidade Veiga de Almeida - Rio de Janeiro, 2021.

FREIRE, Marcella do Amparo Monteiro; LIMA, Michel Lobo Toledo. "O Amor Acaba": Entre Demandas de Direitos e (Não) Reconhecimento de Identidades. In: Formas consensuais de solução de conflitos I [Recurso eletrônico on-line] organização CONPEDI. Coordenadores: Adriana Silva Maillart; Caio Augusto Souza Lara; Diego Mongrell González - Florianópolis: CONPEDI, 2020.

GEERTZ, Clifford. O saber local, fatos e leis em uma perspectiva comparativa. In: $O$ saber local. Petrópolis, Vozes, 2002, p. 249-356. 
LIMA, Michel Lobo Toledo. A Formação do Conhecimento no Campo do Direito e das Ciências Sociais: Questões Teórico-Metodológicas. Revista CONFLUÊNCIAS UFF (NITERÓI), v. 1, p. 41-63, 2015.

Próximo da justiça, distante do direito: administração de conflitos e demandas de direitos no juizado especial criminal. Rio de Janeiro: Autografia, 2017.

LIMA, Roberto Kant de. Ensaios de Antropologia e de Direito: acesso à justiça e processos institucionais de administração de conflitos e produção da verdade jurídica em uma perspectiva comparada. Rio de Janeiro: Lumen Juris, 2008.

Entre as leis e as normas: Éticas corporativas e práticas profissionais na segurança pública e na Justiça Criminal. Revista de Estudos de Conflito e Controle Social. v. 06, n. 04, 2013, p. 549-580.

MADALENO, Rolf. Curso de Direito de Família, 5. ed., Rio de Janeiro: Editora Forense. 2014.

MENDES, Regina Lúcia Teixeira Mendes da. Do princípio do livre convencimento motivado: legislação, doutrina e interpretação de juízes brasileiros. Rio de Janeiro: Lumen Juris, 2012.

Salário Mínimo de Empregada Doméstica 2021. Disponível em: <https://www.idomestica.com/tabelas/salario-empregada-domestica>. Acesso em: 20 mar. 2021.

SHAKESPEARE, William. Romeu e Julieta. Trad. Beatriz Viégas-Faria, Porto Alegre: L\&PM, 2000 .

Superior Tribunal de Justiça. Separação de fato há mais de um ano permite curso da prescrição para pedido de partilha de bens. Disponível em: <https://www.stj.jus.br/sites/portalp/Paginas/Comunicacao/Noticias/Separacao-de-fatotambem-permite-curso-da-prescricao-para-pedido-de-partilha-debens.aspx\#: :text=A\%20separa\%C3\%A7\%C3\%A3o\%20de\%20fato\%20\%C3\%A9,no\%20est ado\%20civil\%20de\%20casados>. Acesso em: 07 mar. 2021.

Superior Tribunal de Justiça. REsp: 1608413 MG 2014/0108027-8. Disponível em: <https://stj.jusbrasil.com.br/jurisprudencia/465614878/recurso-especial-resp-1608413-mg2014-0108027-8/inteiro-teor-465614888 >. Acesso em: 07 mar. 2021. 